\title{
Governança ambiental global: atores e cenários
}

\author{
Global environmental governance: actors and scenarios
}

Julia Vaz Lorenzetti1

Rosinha Machado Carrion²

\section{Resumo}

De natureza teórica, este artigo tem por objetivo analisar desafios que se colocam à consolidação de um sistema de governança ambiental global. Considerando que a questão ambiental diz respeito a um bem público global, sobrepondose, pois, aos limites estabelecidos pelas fronteiras físicas dos Estados-Nação, é dada especial ênfase à análise das questões da participação e da fragmentação da estrutura organizacional do sistema de governança transnacional em vigor atualmente. Para tal, questiona-se em que medida a estrutura criada sob a égide da ONU viabiliza a expressão democrática dos diferentes interesses envolvidos. Após consulta a importantes publicações sobre o tema, a conclusão a qual se chega, apoiada em Hermet (2005) e Kazancigil (2005), é a de que, para fugir da tendência à concentração do poder em grupos que defendem interesses particulares, seria necessário reafirmar a soberania e a legitimidade do campo político.

Palavras-chave: Governança global. Meio ambiente. Participação. Organização das Nações Unidas (ONU).

\begin{abstract}
This theoretical article analyses the challenges to the consolidation of a global environmental governance system. Because the environment is public property that reaches beyond the physical borders of any nation state, special emphasis is placed on analyzing issues regarding participation in and the fragmentation of the organizational structure of the current transnational system of governance. For this purpose, the article asks to what extent the structure created under the auspices of the UN allows the democratic expression of the different interests involved in this matter. After a review of the main publications on the subject, the conclusion reached, based on Kazancigil (2005) and Hermet (2005) is that to curb the trend for the concentration of power among groups defending their own interests, it is necessary to reaffirm the sovereignty and legitimacy of the political field.
\end{abstract}

Keywords: Global governance. Environment. Participation. The United Nations (UN).

Texto submetido em 30 de julho de 2012 e aceito para publicação em 16 de agosto de 2012.

1 Mestre em Administração pela Universidade Federal do Rio Grande do Sul/PPGA; Engenheira Sanitarista e Ambiental pela Universidade Federal de Santa Catarina. Endereço: UFRGS/PPGA - Programa de Pós-Graduação em Administração; Rua Washington Luiz, 855, CEP 90010-460, Porto Alegre - RS, Brasil. E-mail: jvlorenzetti@gmail.com

Pós-Doutora em Estudos do Desenvolvimento pela Université Paris I/IEDES; Doutora em Administração pela Universidade Federal do Rio Grande do Sul/PPGA; Professora-Associada da Universidade Federal do Rio Grande do Sul. Endereço: UFRGS/PPGA Programa de Pós-Graduação em Administração; Rua Washington Luiz, 855, CEP 90010-460, Porto Alegre - RS, Brasil. E-mail: carrion@ea.ufrgs.br 


\section{Introdução}

O tema governança tem sido objeto de debate no que se refere tanto ao seu significado, como à amplitude das questões que envolve. As situações apontadas como de governança indicam a importância da participação dos atores cujos interesses estejam em questão nos processos de tomada de decisões e de gestão.

Rosenau e Czempiel (1992) afirmam que governança não é sinônimo de governo. Segundo eles, a governança seria um fenômeno mais amplo, por envolver, paralelamente, as instituições governamentais e o comprometimento de atores privados e não governamentais.

A problemática ambiental se enquadra como importante temática no âmbito da governança, se considerarmos o meio ambiente ecologicamente equilibrado como um direito humano universal ${ }^{3}$, cuja gestão deve, portanto, contemplar a participação de diferentes atores. Quanto à dimensão transnacional, a questão ambiental desafia as fronteiras e a soberania dos Estados-Nação, ao exigir o reconhecimento da interdependência ecológica entre os territórios globais.

Considerado esse cenário, este artigo, de natureza teórica, tem por objetivo analisar desafios que se colocam à consolidação de um sistema de governança ambiental global, com ênfase na análise das questões da participação e da fragmentação da estrutura organizacional do sistema hoje em vigor, apresentando os atores envolvidos e os papéis que lhes são atribuídos.

\section{Governança}

Esta seção é dedicada à discussão da governança no âmbito da política contemporânea, bem como à apresentação de atores imbricados nesse processo.

\section{Governança e política contemporânea}

O uso do termo "governança" tem origem no mundo empresarial, a partir do artigo The nature of the firm, publicado em 1937 por Ronald Coase, mas que não teve grande repercussão até a década de 1970, quando Oliver Williamson contribuiu para sua redescoberta (MILANI e SOLINÍS, 2002). Apesar da origem corporativa, o termo vem sendo também utilizado por referência a questões como democracia, desenvolvimento e globalização, que envolvem uma pluralidade de atores (ARTURI, 2003; BORGES, 2003; LEFTWICH, 1993; MILANI e SOLINÍS, 2002). A globalização, além de diminuir as fronteiras econômicas, afeta, paralelamente, as dimensões ideológicas, sociais e políticas da vida em sociedade, com consequentes implicações para a gestão.

A Comissão sobre Governança Global (1996, p. 2), em relatório que aborda a necessidade de reformas na cooperação internacional, definiu governança como "a totalidade das diversas maneiras pelas quais os indivíduos e as instituições, públicas e privadas, administram seus problemas comuns. É um processo contínuo pelo qual é possível acomodar interesses conflitantes ou diferentes e realizar ações cooperativas.".

Para Leca (1996), a governança consiste na gestão a partir de uma pluralidade de atores, que não são nem públicos nem privados. Rosenau e Czempiel (1992), ao distinguirem governança de governo, destacam que a governança tem legitimidade apenas se aceita pela maioria ou, pelo menos, por aqueles diretamente afetados, enquanto o governo pode operar mesmo diante da oposição.

\footnotetext{
${ }^{3}$ O artigo III da Declaração Universal dos Direitos Humanos, de 1948, diz que "todo ser humano tem direito à vida", o que pode ser interpretado como direito a um ambiente ecologicamente equilibrado.
} 
Apesar da polissemia que cerca o termo "governança", em um ponto parece existir consenso: ninguém ousa questionar o direito à participação dos cidadãos em situações que afetem suas vidas. A participação instituise como carro-chefe do discurso político em sociedades balizadas pela ideologia democrática, como as ocidentais.

Arturi (2003) ressalta que a globalização econômica e o surgimento de novos atores na cena internacional aos quais, por sua importância na negociação dos processos, Barros (2009) atribui a denominação de "diplomacia civil" - implicaram o questionamento sobre a qualidade da democracia no mundo ocidental e apontaram a urgência da criação de um amplo e democrático espaço público mundial, capaz de incluir também a participação dos atores não estatais.

Todavia, Arturi (2003) argumenta ser ingenuidade acreditar que a descentralização e a participação podem, por si só, trazer soluções para os problemas locais. Seria necessário levar em conta as particularidades de cada caso, pois a democracia, por coerência, não pode ser nem única, nem imposta. Ao discutir os desafios práticos à instalação de um sistema de governança mundial, Arturi (2003) destaca os riscos decorrentes da falta de legitimidade de muitas associações e ONGs que se autointitulam representantes de setores sociais, bem como a tendência de algumas delas se articularem diretamente com instituições internacionais e grandes empresas, em detrimento de órgãos estatais.

Conforme Diniz (2003), atualmente, o grande desafio mundial é o da sustentabilidade da democracia, e para isso importa considerar a dimensão política da reforma do Estado, o que implica ruptura com seu enclausuramento burocrático e abertura à participação da sociedade. A autora defende novos estilos de gestão pública, a partir do fortalecimento das conexões do Estado com a sociedade e instituições dela representativas, bem como da incorporação de novos mecanismos de accountability.

Lançando um olhar mais crítico sobre o debate em torno da governança, Arturi (2003) observa que a ênfase em questões de gestão, sem menção ao papel direto do Estado, tornou esse conceito conveniente à utilização econômica, a cujos interesses as dimensões sociais e democráticas estariam condicionadas. Nesse ponto, ele se aproxima de Hermet, Kazancigil e Prud'Homme (2005) ao analisarem o futuro do regime democrático sob a égide do termo "governança". De acordo com Kazancigil (2005, p. 59), "para sair dessa armadilha seria necessário que o político reafirmasse sua soberania e sua legitimidade face à supremacia do econômico e reencontrasse sua vocação para a coesão social e a justiça redistributiva.".

\section{Atores da governança}

Os processos de globalização alteram profundamente o papel tradicional dos atores não estatais na cena mundial, ao torná-los mais autônomos (MILANI e SOLINÍS, 2002) e interdependentes (MILANI, 1999).

Milani e Solinís (2002) afirmam que as discussões sobre a governança implicam a consideração de novos atores nas questões mundiais. Nesse sentido, propõem que, em nível transnacional, os atores não estatais, principalmente as ONGs, assumam lugar central no espaço público mundial, levantando novas demandas sociais e novas instâncias de regulação sistêmica. Contudo, reconhecem que faltam, ainda hoje, as articulações para que o diálogo entre atores ocorra de modo efetivo (por exemplo, entre as ONGs e os sindicatos).

Hermet (2002), por sua vez, ressalta a importância do papel do Estado na governança, ao defender que os imperativos da constituição de um sistema de governança mundial não devem se sobrepor às prerrogativas do Estado, destacando ainda os riscos que isso implica para a consolidação do processo democrático, em particular, para os países periféricos.

Ao analisar as práticas do Banco Mundial diante das questões da governança e da participação, Borges (2003) coloca que, ainda que a instituição tenha passado a aceitar a dependência de seu modelo de desenvolvimento às dinâmicas políticas e sociais locais, e a incentivar o empowerment da sociedade civil, 
essas práticas configuram uma participação discursiva, na medida em que o que deverá ser feito, assim como os espaços reservados à participação, são pré-definidos pelo Banco. Paralelamente, o autor aponta ainda que, embora o BM utilize a retórica do "desenvolvimento apolítico", as reformas que orienta têm implicações políticas claras, pois revelam uma preferência normativa por atributos da democracia ocidental (liberal e capitalista) e pela racionalidade dos princípios de mercado, o que condiciona o termo "governança" aos objetivos do liberalismo econômico.

Arturi (2003), por sua vez, acredita que, para instaurar a governança mundial democrática, seria necessária a precedência do político sobre o econômico na construção do espaço público mundial. Ele defende, ainda, que a tentativa de reforço das sociedades civis no cenário internacional não deve ocorrer em detrimento dos Estados nacionais e das instituições governamentais.

\section{Problemática Ambiental}

$\mathrm{O}$ crescente número de questões com implicações transfronteiriças ou globais torna necessária uma articulação internacional para a condução também de problemas ambientais (ESTY e IVANOVA, 2005). Abdala (2007) compartilha esse posicionamento ao argumentar que o reconhecimento da interdependência ecológica entre os continentes requer ações coletivas nas dimensões socioeconômicas, políticas e ambientais.

A base conceitual subjacente aos problemas ambientais é a noção de bem público. Segundo Kaul, Grunberg e Stern (1999 apud ESTY e IVANOVA, 2005, p. 217), bens públicos globais são "bens cujos benefícios transpõem fronteiras, gerações e grupos populacionais".

Trata-se de uma problemática que desafia as fronteiras e a soberania dos Estados, pois para o meio ambiente não existem fronteiras geopolíticas. Essa constatação pode ser observada a partir da análise de diversos elementos ambientais. O aquífero Guarani, por exemplo, está presente em quatro países: Brasil, Argentina, Uruguai e Paraguai. Nas águas superficiais também encontramos exemplos de compartilhamento de bens ambientais: a bacia hidrográfica do rio Níger, no continente africano; a bacia do rio Paraguai, na América Latina; e a bacia do rio Danúbio, na Europa, fluem, cada uma, ao longo de mais de dois países.

A questão das mudanças climáticas vem sendo amplamente abordada pelos meios de comunicação e ilustra um importante exemplo do caráter global das questões ambientais. Os níveis de concentração dos gases do efeito estufa já são preocupantes, e o aumento da temperatura média do planeta até 2100 pode culminar em drásticas alterações do ambiente (INTERGOVERNMENTAL PANEL ON CLIMATE CHANGE, 2007), como por exemplo: a mudança na dinâmica dos ventos, o aumento do nível dos mares, a alteração do regime das chuvas e o desencadeamento de epidemias, entre outros fenômenos (GIDDENS, 2010; MOTTA et al, 2011).

Motta et al (2011) destacam que a minimização dos impactos advindos da mudança do clima requer um esforço global, apesar de não haver consenso sobre como operacionalizá-lo. Os autores associam esse cenário à "tragédia dos comuns", termo cunhado em 1968 por Garrett Hardin ao se referir a uma situação em que a falta de cooperação entre ações individuais culmina numa situação desastrosa para o coletivo.

O controle sobre o aumento do buraco da camada de ozônio, por sua vez, é um exemplo de que a ação conjunta de diversos atores pode prover resultados positivos. Em 2010, a comunidade científica constatou que na última década a área média do buraco permaneceu estabilizada (NOVAES, 2010).

O caráter global e transfronteiriço do meio ambiente pode levar a conflitos, seja devido à disputa por recursos, seja devido aos constrangimentos que impõe em termos tanto das tecnologias produtivas e do uso do solo, como das formas de consumo adotadas pelos países ricos. Na África, por exemplo, a Etiópia abriga a nascente do Nilo Azul, enquanto Uganda possui a nascente do Nilo Branco, e ambos os países desejam utilizar essa situação geográfica para se desenvolver. O Egito, por sua vez, tem nas águas do rio Nilo mais da metade da fonte de seus recursos hídricos, e junto com o Sudão - país onde confluem o Nilo Branco e o Nilo 
Azul - detém 87\% das águas desse manancial (PRIER, 2010; TAGUCHI, 2010). O conflito entre Israel e Palestina também é permeado por questões ambientais, pois ambos os territórios utilizam as águas do rio Jordão, que sofre com a poluição e a escassez, numa disputa que também envolve Síria, Líbano e Jordânia. (BBC, 2003; ECHEVENGUÁ, 2011; ZECCHINI, 2009).

Nesse cenário, urge o debate sobre governança global do meio ambiente.

\section{Questão Ambiental na Agenda Internacional}

A agenda ambiental internacional conta com importantes momentos oficiais, referentes a conferências internacionais. Esta seção é dedicada à apresentação destes eventos.

\section{Conferência das Nações Unidas sobre o meio ambiente humano}

No fim da década de 1960, a Suécia e outros países nórdicos propuseram uma conferência internacional sobre o meio ambiente, que foi realizada em 1968 sob a coordenação da UNESCO. A essa conferência se seguiu a Conferência das Nações Unidas sobre o Meio Ambiente Humano, realizada em Estocolmo, no ano de 1972, que foi responsável por colocar as questões ambientais na agenda dos países membros da ONU (KARNS e MINGST, 2010).

Como resultado, a conferência de 1972 gerou a Declaração de Estocolmo, documento com 26 princípios que destaca, entre outros aspectos, a importância dos Estados e organizações internacionais protegerem o meio ambiente (CONFERÊNCIA DAS NAÇÕES UNIDAS SOBRE O MEIO AMBIENTE HUMANO, 1972). Paralelamente à Declaração, outro resultado da conferência foi a criação de um novo programa das Nações Unidas para coordenar as atividades ambientais e promover a cooperação: o Programa das Nações Unidas para o Meio Ambiente/PNUMA. O slogan "pense globalmente, aja localmente" tornou-se um símbolo do evento (KARNS e MINGST, 2010).

O debate entre os diferentes atores não se daria, todavia, de modo tranquilo, pois enquanto os países centrais enfatizavam aspectos como a preservação das espécies e a necessidade de reduzir a poluição ambiental, os emergentes e periféricos temiam que a regulamentação ambiental viesse a comprometer seu crescimento econômico. Durante as reuniões preparatórias para a conferência de 1972, o secretário geral do evento, Maurice Strong, procurou fazer a ponte entre os interesses em conflito através do estabelecimento de vínculos conceituais entre desenvolvimento e meio ambiente. Contudo, o aparente consenso de Estocolmo sobre a integração desses conceitos não teria sido totalmente aceito, seja pelo Centro, pela periferia, ou ainda pelos países emergentes (KARNS e MINGST, 2010).

O acirramento da tensão levou a uma Assembleia da ONU, em 1983, para estabelecer a Comissão Mundial sobre Meio Ambiente e Desenvolvimento. Quatro anos depois, a Comissão apresentou um relatório que instituiu o conceito de desenvolvimeno sustentável e se tornou conhecido como "Relatório Brundtland ou Nosso Futuro Comum" (INTERNATIONAL INSTITUTE FOR SUSTAINABLE DEVELOPMENT, 2010). Neste relatório, a Comissão teve a árdua tarefa de procurar equilibrar as preocupações ecológicas com o crescimento econômico necessário para reduzir a pobreza.

\section{Conferência das Nações Unidas sobre meio ambiente e desenvolvimento}

Após a Conferência de Estocolmo, vinte anos se passaram até a realização da Conferência sobre Meio Ambiente e Desenvolvimento - também chamada de Cúpula da Terra e Rio 92 -, na cidade do Rio de Janeiro. Convocada a partir de uma série de importantes descobertas científicas na década de 1980 - como a do buraco na camada de ozônio sobre a Antártida, a crescente evidência das alterações climáticas e os dados 
acumulados sobre a perda da biodiversidade -, a conferência marcou um importante momento na tentativa de se chegar a um consenso capaz de conciliar interesses dos países centrais, periféricos e semiperiféricos. Como resultados desse evento podem ser citados: a Agenda 21, a Convenção sobre Diversidade Biológica, a Convenção-Quadro das Nações Unidas sobre Mudanças Climáticas e a Declaração do Rio de Janeiro. Além disso, devido à articulação que se estabelecia entre promoção do desenvolvimento e preservação do meio ambiente, a questão ambiental foi expandida ao Banco Mundial (KARNS e MINGST, 2010; INTERNATIONAL INSTITUTE..., 2010).

A Cúpula da Terra foi de particular importância para as ONGs, enquanto a Agenda 21 estabeleceu que o compromisso e a participação genuína de atores não estatais são fundamentais para se atingir as metas de desenvolvimento sustentável. Nesse evento, foram credenciadas grandes ONGs, mas também novos grupos que possuíam poucas ligações transnacionais anteriores (KARNS e MINGST, 2010).

Por fim, em 1993, como resultado dessa conferência, foi criada no âmbito da ONU a Comissão de Desenvolvimento Sustentável (CDS), com as atribuições de incentivar e acompanhar a implementação da Agenda 21 e da Declaração do Rio de Janeiro (UN DEPARTMENT OF ECONOMIC AND SOCIAL AFFAIRS, 2009).

\section{Cúpula mundial sobre desenvolvimento sustentável}

A Cúpula Mundial sobre Desenvolvimento Sustentável, realizada em 2002 na cidade de Johannesburgo, teve como objetivo propor ações para acelerar e fortalecer os princípios debatidos no Rio de Janeiro em 1992, e resultou em dois documentos: a Declaração de Johannesburgo e o Plano de Implementação (LAGO, 2006; ONU NO BRASIL, 2012). O Plano reafirma o compromisso com os objetivos da Conferência das Nações Unidas sobre Meio Ambiente e o Desenvolvimento. Também apresenta metas como reduzir pela metade, até 2015, a proporção de pessoas sem acesso à água potável no mundo e promover a utilização de energias renováveis (CÚPULA MUNDIAL SOBRE DESENVOLVIMENTO SUSTENTÁVEL, 2002).

Após duas conferências internacionais cujos resultados pareciam refletir avanços na governança ambiental global, a Cúpula de Johannesburgo apresentou resultados decepcionantes. Todavia, se por um lado, os atores reunidos em Joanesbusgo pareciam motivados pela esperança de conter o crescimento da pobreza e reduzir a poluição e o desmatamento acelerado na década de 1990, as ONGs não tiveram autorizaçao para participar plenamente, o que aprofundou a desilusão acerca da viabilidade do desenvolvimento sustentável (KARNS e MINGST, 2010).

\section{Conferência das Nações Unidas sobre desenvolvimento sustentável}

Em 2012, a cidade do Rio de Janeiro sedia novamente uma conferência internacional ambiental, a Conferência das Nações Unidas sobre Desenvolvimento Sustentável, também chamada de Rio+20 por ter sido realizada 20 anos após a Conferência das Nações Unidas sobre Meio Ambiente e Desenvolvimento, a Rio 92.

O encontro de 2012 teve o objetivo de renovar o compromisso político com o desenvolvimento sustentável, e seus temas principais foram: 1) a economia verde no contexto do desenvolvimento sustentável e da erradicação da pobreza; 2) a estrutura institucional para o desenvolvimento sustentável. Delegações de 188 Estados membros da ONU participaram do evento (RIO+20, 2012). Contudo, o presidente dos EUA, Barack Obama, a chanceler alemã, Angela Merkel, e o primeiro ministro britânico, David Cameron, não estiveram presentes.

Nessa conferência, o governo brasileiro, com apoio das Nações Unidas, organizou o espaço "Diálogos para o Desenvolvimento Sustentável", voltado para a participação da sociedade civil através da elaboração de 
recomendações sobre temas prioritários relativos ao desenvolvimento sustentável, a serem encaminhadas aos chefes de Estado e de governo presentes no evento (RIO+20, 2012).

Durante a realização da Rio+20, eventos paralelos aconteceram na cidade do Rio de Janeiro, como a Cúpula dos Povos e o encontro da rede internacional C40 - Cities Climate Leadership Group.

A Cúpula dos Povos - na Rio+20 por Justiça Social e Ambiental foi organizada por entidades da sociedade civil que consideraram a proposta oficial da conferência de enfatizar a economia verde insuficiente para tratar dos problemas socioambientais enfrentados pela humanidade. As ações da Cúpula foram organizadas a partir de três eixos principais, que se propunham a: 1) denunciar as causas estruturais das crises; 2) propor soluções e novos paradigmas dos povos; e 3) estimular organizações e movimentos sociais a articular processos de luta pós-Rio+20 (CÚPULA DOS POVOS, 2012).

A C40, por sua vez, é uma rede global de grandes cidades do mundo - como São Paulo, Hong Kong e Nova York - que visam adotar medidas para reduzir as emissões de gases de efeito estufa e os riscos climáticos. $\mathrm{Na}$ Rio+20, prefeitos integrantes da $\mathrm{C} 40$ realizaram um encontro onde foram apresentadas metas de redução da emissão de gases de efeito estufa (C40, 2012).

O documento final da conferência, denominado "O Futuro que Queremos", foi criticado por atores da sociedade civil. Um grupo de ambientalistas, ativistas e cientistas com atuação de destaque em relação à temática ambiental protocolou uma carta a chefes de governo e de Estado manifestando insatisfação com o resultado das negociações e com o documento final da conferência (RADAR RIO+20, 2012).

\section{Atores da Governança Ambiental Global}

Esta seção é dedicada à apresentação de atores da governaça ambiental global. Os Estados-Nação não serão aqui abordados, dado que sua relevância - quando o objeto de debate é a governança - já foi referida em seção anterior. Essa opção não pretende, todavia, subestimar a importância dos Estados, os quais, segundo Karns e Mingst (2010), se mantêm como atores-chave na governança global. Entretanto, também de acordo com os autores, para que haja legitimidade nesse processo, faz-se necessário ampliar o escopo da participação, para assegurar a representatividade da sociedade civil.

\section{Instituições da ONU}

Karns e Mingst (2010) afirmam que a Organização das Nações Unidas é a peça central da governança global desde a II Grande Guerra, sendo a única organização intergovernamental de abrangência e adesão quase universais, cuja agenda inclui diversas questões relativas à governança. $\mathrm{O}$ mesmo é observado quanto à questão do meio ambiente, levando-se em conta uma série de organizações e programa existentes no âmbito da ONU, alguns deles apresentados nesta seção.

O Programa das Nações Unidas para o Meio Ambiente foi criado a partir da Conferência sobre Meio Ambiente Humano, em Estocolmo, e sua missão é prover liderança, bem como estimular parcerias visando ao cuidado com o meio ambiente (UNITED NATIONS ENVIRONMENT..., 2010). A sede do programa foi instalada em Nairóbi, no Quênia, tornando-se a primeira agência da ONU instalada num país em desenvolvimento (KARNS e MINGST, 2010).

Com a finalidade de acompanhar a implantação da Agenda 21, surgiu, a partir da Conferência Rio-92, a Comissão para o Desenvolvimento Sustentável (CDS). Essa comissão tem ainda as atribuições de dar orientação política sobre iniciativas futuras, promover a discussão e também orientar a formação de parcerias para o desenvolvimento sustentável entre os diversos atores (KARNS e MINGST, 2010). 
Em termos de iniciativas políticas, a CDS tem assumido um importante papel em áreas ambientais não gerenciadas por uma convenção específica, como a gestão da água doce (FÓRUM BRASILEIRO DE ONGs..., 2007).

Contudo, a comissão não tem autoridade para obrigar os Estados a agirem e não possui o comando de seus recursos financeiros. Seus delegados são provenientes dos ministérios do meio ambiente dos países participantes, que tradicionalmente são ministérios menos poderosos. Dessa forma, Karns e Mingst (2010) argumentam que intituições econômicas como o Banco Mundial e a Organização Mundial do Comércio teriam maior poder, no que diz respeito às questões ambientais, do que a própria CDS.

Os acordos ambientais são instrumentos que auxiliam a resolução de problemáticas ambientais, e, atualmente, existem mais de quinhentos acordos ambientais internacionais (FÓRUM BRASILEIRO DE ONGs..., 2007). Cada acordo dispõe de um secretariado que organiza as conferências das partes, recebe inscrições de participação e responde pela gestão administrativa.

\section{Instituições econômicas internacionais}

As instituições econômicas multilaterais, seus mecanismos e políticas, de acordo com o Fórum Brasileiro de ONGs... (2007), desestabilizaram as estruturas econômicas de muitos países em desenvolvimento através de condicionalidades vinculadas a créditos e empréstimos, com o que teriam contribuído para a degradação ambiental e a exclusão social.

Karns e Mingst (2010) referem-se à busca do Banco Mundial pela sustentabilidade como "uma estrada rochosa". Trata-se do maior doador multilateral para o chamado "desenvolvimento econômico", e, desde 1993, seus empréstimos para programas ambientais aumentaram, incluindo, por exemplo, programas para redução da poluição industrial na província de Liaoning, na China. Entretanto, o comprometimento desta instituição com a sustentabilidade ambiental ainda é questionável. Weaver (2008 apud KARNST e MINGST, 2010, p. 518) aponta "incrongruências dos objetivos de desenvolvimento sustentável com a cultura intelectual e operacional do Banco", e Karns e Mingst (2010) estendem essa observação à Organização Mundial do Comércio. Também Borges (2003), conforme já referido, ao analisar a atuação do Banco Mundial diante do tema governança, apresenta considerações que vão ao encontro da análise de Weaver (2008).

Segundo o Fórum Brasileiro de ONGs... (2007), para que instituições econômicas internacionais adotem políticas que respeitem as diretrizes ambientais da ONU, é necessário que: a) cada Estado membro da ONU crie condições de maior internalização dos compromissos dos regimes multilaterais ambientais; b) sejam fortalecidas de maneira formal e efetiva as condições de governança na atuação dos diversos organismos e instâncias do sistema ONU, respaldando-os diante das instituições de Bretton Woods e da Organização Mundial do Comércio.

\section{Fundo global para o meio ambiente}

O Fundo Global para o Meio Ambiente (The Global Environment Facility - GEF) foi criado como o principal mecanismo internacional de financiamento para projetos e programas que protejam o meio ambiente em países em desenvolvimento e em transição. Os subsídios são concedidos em cinco áreas prioritárias: camada de ozônio, águas internacionais, biodiversidade, mudanças climáticas e poluentes orgânicos persistentes (KARNS e MINGST, 2010).

O Banco Mundial é o principal parceiro na administração do GEF. Entretanto, o fundo conta com a colaboração de outras instituições, como o PNUMA, que atua na área de supervisão científica e através do GEF apoia diversos países no cumprimento das obrigações assumidas em convenções ambientais e na criação de capacidades para implementá-las (FÓRUM BRASILEIRO DE ONGs..., 2007). 


\section{Setor privado}

O setor privado corresponde a atores cujos interesses econômicos são diretamente afetados pela regulação ambiental. Historicamente, são vistos como opositores às políticas ambientais, pois utilizariam sua influência para vetar ou enfraquecer os regimes ambientais. A partir dos anos 1990, Kofi Annan, então secretário-geral da ONU, incentivou uma maior cooperação institucional com o setor privado no processo de reforma da governança ambiental global, de modo que este pudesse ser visto não mais como um problema adicional, mas sim como um ator capaz de cooperação e inovação (ANDRADE, 2009).

Para ter acesso à arena internacional de negociações ambientais, o setor privado articula-se através de associações empresariais. Sua participação ocorre, por exemplo, pela elaboração de relatórios e pela cooperação com delegações nacionais. Entretanto, essa participação não ocorre sem que haja tensões, principalmente, devido ao questionamento da legitimidade da iniciativa privada como defensora de interesses coletivos.

Para transpor esse obstáculo, o setor privado tem procurado apresentar contribuições através, por exemplo, de inovação tecnológica, como o desenvolvimento de substitutos para os CFCs - poluentes nocivos à camada de ozônio -, e de práticas de responsabilidade socioambiental (ANDRADE, 2009).

Carrieri, Silva e Pimentel (2009), ao pesquisarem o discurso sobre a responsabilidade socioambiental nas organizações, deduziram que tal responsabilidade já permeia as organizações e está presente no discurso e na prática da alta direção, dos gerentes e de boa parte dos técnicos. No entanto, concluíram também que os limites dessa responsabilidade aparecem na fala de técnicos que se sentem ameaçados quando tal compromisso interfere em seus objetivos particulares.

\section{Sociedade civil}

A composição da sociedade civil é bastante diversificada. Compreende desde pessoas físicas até instituições religiosas e acadêmicas, sem contar os grupos de interesse específicos, como as ONGs. Para Cohen e Arato (1992), o termo é geralmente usado para classificar pessoas, instituições e organizações que têm como meta fomentar ou expressar um objetivo comum mediante ideias, ações e exigências aos governos.

Gemmill e Bamidele-Izu (2005) identificaram cinco principais papéis que a sociedade civil pode desempenhar na governança ambiental global. São eles: 1) coletar, difundir e analisar informação; 2) fornecer dados para a fixação de agenda e para os mecanismos de desenvolvimento de políticas; 3) desempenhar funções operacionais; 4) avaliar as condições do meio ambiente e monitorar o cumprimento de acordos ambientais; e 5) pleitear justiça ambiental.

A Conferência Rio-92 foi um marco no reconhecimento das contribuições da sociedade civil para a governança ambiental. O Princípio 10 da Declaração do Rio defende que temas ambientais são melhor tratados quando conseguem mobilizar e levar a uma participação integrada da pluralidade de atores que compõem a sociedade.

Badie (2009), através da reconstrução histórica do escopo das relações internacionais, aponta que de assunto exclusivamente interestatal, elas passaram a exprimir uma nova forma de integração social internacional, baseada também nos avanços tecnológicos da comunicação. O autor argumenta que a presença da "sociedade internacional" na arena das relações internacionais não seria bem aceita pelos Estados, na medida em que tende a ser percebida como uma ameaça à soberania nacional. Badie (2009) propõe o termo "mundialização" em substituição ao termo "globalização", na medida em que o primeiro traz a propriedade de abrir as sociedades umas às outras, observando que as ONGs poderiam ser consideradas atores-chave nessas relações capilarizadas. 
Segundo Gemmill e Bamidele-Izu (2005), no âmbito da governança ambiental, as ONGs são os atores com maior destaque. Entretanto, os mecanismos formais previstos para a sua participação, no contexto da ONU, continuam limitados. Os autores defendem que a participação da sociedade civil deve ocorrer através de uma estrutura de engajamento mais formalizada e institucional, que requer um comprometimento significativo de tempo, além de recursos financeiros de governos e organismos intergovernamentais. Eles propõem a utilização de formas inovadoras de rede, por meio de coalizões regionais, para ajudar a promover a inclusão de uma multiplicidade de vozes.

Oliveira (2012), ao analisar a participação da sociedade civil - ainda na fase de elaboração dos documentos preparatórios para a Rio+20-, constatou que em relação à produção dos documentos oficiais, essa participação é desordenada e pouco efetiva. A autora defende que esse cenário poderia ser modificado a partir de chamadas por temas específicos e da indicação de setores com potencial envolvimento com o tema, o que contribuiria para a organização da sociedade civil em redes.

No âmbito local, ações da sociedade civil com implicação global e finalidade de influenciar decisões que perpassam questões ambientais são observadas com frequência crescente. Em Florianópolis, a comunidade se articulou intensamente contra a construção de um estaleiro da empresa OSX, que seria o maior empreendimento privado no estado de Santa Catarina. O local escolhido para a instalação do estaleiro era a Baía de São Miguel, próximo a três unidades de conservação. A sociedade civil e o ICMBio - autarquia criada em 2007 e vinculada ao Ministério do Meio Ambiente - levantaram uma série de prejuízos ambientais que a obra causaria. Forçado pelo clamor da opinião pública, o empresário responsável pelo empreendimento acabou desistindo de estabelecer o estaleiro naquela localidade.

Há indicativos de que não somente aspectos técnicos o fizeram mudar de opinião, mas também o posicionamento contrário de segmentos da sociedade (KAFRUNI, 2010). Por outro lado, é possível observar a carência de recursos e até de interesse da sociedade civil em participar das decisões acerca do ambiente.

Santana, Guedes e Villela (2011) investigaram a atuação do poder local em relação a grandes empreendimentos em Itaguaí (RJ). Constataram baixa participação de atores locais no desenvolvimento do município, observando no caso específico da sociedade civil, uma carência de participação popular e de interesse pelo desenvolvimento sustentável. Os autores apresentaram instrumentos que poderiam ser utilizados para reverter essa situação, como a Agenda 21 Local, que implica a participação de atores de diferentes segmentos da sociedade, cuja criação estava em andamento por iniciativa do poder público.

O setor judiciário também pode ser apresentado como um ator da sociedade civil na governança ambiental global. Há iniciativas externas ao contexto formal, como é o caso do Tribunal Latino-Americano da Água. Trata-se de uma organização internacional autônoma, de justiça ambiental independente, criada para ajudar a resolver disputas relacionadas à água, atuando, inicialmente, na América Latina. O tribunal foi oficialmente constituído em 1998, e desde então tem realizado audiências, além de outras atividades (TRIBUNAL DEL AGUA, 2009).

\section{Arquitetura da Governança Ambiental Global}

Ao se analisar a arquitetura do regime de governança ambiental global, observa-se: sua fragmentação, a ênfase nas instâncias formais de participação e a carência de recursos; aspectos esses que são o tema desta seção.

Esty e Ivanova (2005) pontuam que, se algumas das atuais deficiências poderiam ser atribuídas a um histórico de questões administrativas e burocráticas, há outras dimensões do problema que são de natureza mais profunda e estrutural.

Comparado com outros regimes - como o de saúde e o de comércio, por exemplo -, a arquitetura para o regime do meio ambiente careceria de articulação e coerência. Simultaneamente, observa-se que a resolução 
de problemas ambientais está dispersa por uma grande quantidade de acordos ambientais internacionais e suas instituições, e que as atividades de cada área temática são coordenadas a partir de diferentes locais no mundo, o que traz dificuldades de comunicação e coordenação.

Ainda que a fragmentação da estrutura apresente vantagens (como o tratamento mais próximo das demandas da sociedade civil), por outro lado, dificulta o processo de coordenação das decisões. Além disso, não raramente demanda trabalho em dobro, aumenta os custos administrativos para os países-membros e exige um maior número de reuniões e de relatórios, criando um emaranhado tal, que dificulta não apenas compreender o processo, mas também dele participar.

Em detrimento da configuração atual, em que as responsabilidades ambientais estão distribuídas por diversas instituições, está em debate a criação de uma instituição única: a Organização das Nações Unidas para o Meio Ambiente (ONUMA), vinculada ao sistema ONU, para articular e organizar a abordagem da temática ambiental. Essa organização teria poderes mais abrangentes e maior capacidade de exigir cumprimento de medidas ambientais. O Fórum Brasileiro de ONGs (2007) argumenta que o PNUMA, a organização hoje existente no espaço da $\mathrm{ONU}$, não tem autoridade executiva nem força política para atuar como órgão internacional líder na proteção do meio ambiente global.

No caso do Brasil, por exemplo, onde há um ministério específico para questões ambientais, pode-se refletir sobre a estrutura centralizada através do caso do licenciamento ambiental de duas usinas hidrelétricas na bacia do rio Madeira, localizada no norte do país, na ocasião em que Marina Silva, então ministra do Meio Ambiente, foi motivo de ironia do presidente da República ao defender os peixes desse rio. Por outro lado, a especificidade desse ministério permite um tratamento aprofundado das questões ambientais brasileiras.

Conforme Esty e Ivanova (2005), o problema não é a existência de várias organizações com responsabilidades no campo ambiental, mas sim a ausência de mecanismos eficientes de coordenação e de troca de informações; portanto, de governança.

Quanto às instâncias de participação, devido à dificuldade de participar das instâncias decisórias formais, a sociedade civil acaba criando arenas paralelas. Como exemplo, apresenta-se o Klimafórum, evento liderado pela sociedade civil que foi originado na $15^{-}$Conferência das Partes sobre Mudanças Climáticas, em Copenhague, e manteve-se na $16^{-}$Conferência, em Cancun, com o objetivo de discutir, paralelamente, temáticas relacionadas à sustentabilidade e às mudanças climáticas (INSTITUTO MAIS, 2010).

Até mesmo nas instâncias formais de participação, há diferenças no acesso ao processo deliberativo. Segundo o Fórum Brasileiro de ONGs (2007), o Fundo Global para o Meio Ambiente sofre de um déficit de governança interna, pois os países em desenvolvimento têm participação restrita nas negociações sobre a reposição de fundos.

O financiamento do sistema de governança ambiental global apresenta-se, também, como um desafio à consolidação do processo de governança. O orçamento anual do PNUMA é menor que o orçamento de grandes ONGs internacionais, como Greenpeace e WWF (World Wide Fund For Nature ou Fundo Mundial para a Natureza).

Diante desse cenário, o Fórum Brasileiro de ONGs (2007) recomenda que os países desenvolvidos promovam transferência de recursos e tecnologia aos países em desenvolvimento, e que o PNUMA receba financiamento adequado à sua importância. Além disso, cogita a criação de um novo fundo de financiamento com uma estrutura inovadora, que contemple mecanismos democráticos de votação e participação. Por fim, os coordenadores do fórum destacam que especial atenção deve ser dada ao aprimoramento das condições de governança nos sistemas de financiamento existentes.

Ao refletiram sobre os problemas anteriormente referidos, Esty e Ivanova (2005) recomendam a criação de um mecanismo, ou sistema de governança global do meio ambiente, calcado nas tecnologias e nas redes da era da informação e que ofereça respostas aos problemas nacionais e às exigências especiais das questões transfronteiriças. 


\section{Considerações Finais}

O debate desenvolvido neste artigo enseja algumas constatações e reflexões. Inicialmente, observa-se a urgência da construção de decisões relativas à implantação de um efetivo sistema de governança ambiental global, capaz de assegurar a participação de atores representativos dos diferentes interesses envolvidos quando o tema é a proteção do meio ambiente. O debate se estende, eivado de disputas e de insatisfações, mas o que é mais grave: sem que o sistema de governança socialmente construído para responder aos desafios ambientais que ameaçam o planeta se demonstre capaz de atender, seja à urgência da situação, seja ao clamor da sociedade por uma efetiva participação. O que nos leva a questionar se Hermet $(2005$, p. 35) não teria razão ao associar o termo "governança" à imagem de um processo "de organizações, por organizações e para as organizações - sejam elas públicas ou privadas, empresariais ou associativas, com ou sem fins lucrativos" -, o qual assumiria as características "de um jogo, progressivamente codificado e no interior do qual as autoridades públicas clássicas têm cada vez mais dificuldade para fazer valer seus recursos específicos".

Por outro lado, compartilhamos a crença no slogan da conferência de Estocolmo, que coloca ser fundamental agir localmente para vislumbrar benefícios globais. Isso implica também criar espaço no âmbito das decisões globais para que sejam consideradas as especificidades locais, inclusive, no que se refere às formas de participação. Como aponta Fernandes (1994), com base na análise da sociedade brasileira, ao limitar-se a participação apenas aos atores formalmente organizados em instituições, corre-se o risco de desconsiderar parcelas especialmente significativas da sociedade.

Caberia, pois, rever os atributos exigidos como condição ao direito de participar dos fóruns internacionais, de modo a tornar possível também a participação de novos movimentos sociais.

Postulamos que maior dedicação acadêmica deve ser direcionada às contribuições das instâncias informais, na medida em que tais espaços têm apresentado vigor ímpar, principalmente, através das configurações sociais em rede.

Quanto à participação do setor privado na governança ambiental, atenção especial deve ser dada à análise da legitimidade das intenções desses atores. Não podemos esquecer que a referência à "responsabilidade social”, não raramente, oculta interesses meramente mercadológicos.

Já no que se refere às propostas aventadas para superar-se o problema da fragmentação, questionamos se a centralização das decisões em uma única organização, a ONUMA, qualificaria o referido processo, ao passo em que são indiscutíveis os benefícios passíveis de serem conquistados através das estruturas em rede.

A conclusão a qual se chega é que a superação dos problemas tratados neste artigo, no que diz respeito tanto à fragmentação do processo decisório, quanto à arquitetura da participação, requer estudos mais aprofundados sobre os reais interesses subjacentes ao uso do termo "governança" diante das questões ambientais - muitas vezes problematizadas em termos econômicos em detrimento de sua condição de direito humano universal. 


\section{Referências}

ABDALA, F. de A. Governança global sobre florestas: o caso do Programa Piloto para Proteção das Florestas Tropicais do Brasil - PPG7 (1992-2006). Tese (Doutorado) - Departamento de Instituto de Relações Internacionais, Universidade de Brasília, Brasília, DF, 2007.

ANDRADE, J. C. S. Participação do setor privado na governança ambiental global: evolução, contribuições e obstáculos. Contexto Internacional, v. 31, n. 2, p.215-250, 2009.

ARTURI, C. S. Os desafios para a instauração de uma governança mundial democrática na atual conjuntura internacional. Revista Indicadores FEE, v. 31, n. 1, p.75-94, 2003.

ASSEMBLEIA GERAL DAS NAÇÕES UNIDAS. Declaração universal dos direitos humanos, Paris, 1948.

BADIE, B. O diplomata e o intruso: a entrada da sociedade na arena internacional. Salvador: Edufba, 2009. 282p.

BARROS, F. L. de. Cooperação internacional e sociedade civil no Brasil: Algumas características da experiência brasileira e apontamentos preliminares para incursões em outros cenários latino-americanos. Congress of the Latin American Studies Association. Rio de Janeiro, 2009. p. 28. Mimeografado.

BBC. Notícias. Palestinos e israelenses travam guerra silenciosa por água. 2003. Disponível em: <http://www.bbc.co.uk/portuguese/noticias/030616_palestinabg.shtml>. Acesso em: 12 nov. 2011.

BORGES, A. Governança e política educacional: a agenda recente do Banco Mundial. Revista Brasileira de Ciências Sociais, v. 18, n. 52, p. 125-138, 2003.

CARRIERI, A. de P.; SILVA, A. R. L. da; PIMENTEL, T. D. O tema da proteção ambiental incorporado nos discursos da responsabilidade social corporativa. Revista de Administração Contemporânea, v. 13, n. 1, p.1-16, 2009.

COHEN, J. L.; ARATO, A. Civil society and political theory. Cambridge: MIT Press, 1992.

COMISSÃO SOBRE GOVERNANÇA GLOBAL. Nossa Comunidade Global. Relatório da Comissão sobre Governança Global. Rio de Janeiro: Fundação Getulio Vargas, 1996.

CONFERÊNCIA DAS NAÇÕES UNIDAS SOBRE O MEIO AMBIENTE HUMANO, 1972, Estocolmo. Declaração da Conferência das Nações Unidas sobre o Meio Ambiente Humano. Estocolmo, 1972.

CONFERÊNCIA DAS NAÇÕES UNIDAS SOBRE MEIO AMBIENTE E DESENVOLVIMENTO, 1992, Rio de Janeiro. Declaração do Rio sobre Meio Ambiente e Desenvolvimento. Rio de Janeiro, 1992.

CÚPULA DOS POVOS. Portal da Cúpula dos Povos - na Rio+20 por justiça social e ambiental. Disponível em: < http://cupuladospovos.org.br/>. Acesso em: 2 jul. 2012.

CÚPULA MUNDIAL SOBRE DESENVOLVIMENTO SUSTENTÁVEL, 2002, Johannesburgo. Plano de implementação da Cúpula Mundial sobre Desenvolvimento Sustentável. Johannesburgo, 2002.

C40 - The C40 Cities Climate Leadership Group. Portal C40. Disponível em: $<$ http://www.c40cities.org/home >. Acesso em: 5 jul. 2012.

DINIZ, E. Reforma do Estado e governança democrática: em direção à democracia sustentada. Conferência Internacional sobre Democracia, Gobernanza y Bienestar en las Sociedades Globales. Reforma del Estado y gobernanza democrática: hacia la democracia sostenible? Barcelona, 2003.

ECHEVENGUÁ. A. A água como arma de guerra. Observatório Eco. 2011. Disponível em: $<$ http://www.observatorioeco.com.br/a-agua-como-arma-de-guerra/>. Acesso em: 15 nov. 2011.

ESTY, D. C.; IVANOVA, M. H. Revitalização da governança ambiental global: um enfoque baseado em funções. In: ESTY, D. C.; IVANOVA, M. H. Governança ambiental global: opções e oportunidades. São Paulo: Senac São Paulo, 2005. p. 207-231. 
FERNANDES, R. C. Privado porém público: o terceiro setor na América Latina. Rio de Janeiro: Relume-Dumará; 1994.

FÓRUM BRASILEIRO DE ONGS E MOVIMENTOS SOCIAIS PARA O MEIO AMBIENTE E O DESENVOLVIMENTO - FBOMS (Org.). Governança ambiental internacional: perspectivas, cenários e recomendações. Brasília, DF, 2007.

GEMMILL, B.; BAMIDELE-IZU, A. O papel das ONGS e da sociedade civil na governança ambiental global. In: ESTY, D. C.; IVANOVA, M. H. Governança ambiental global: opções e oportunidades. São Paulo: Senac São Paulo, 2005. p. 89-113.

GIDDENS, A. A política da mudança climática. Rio de Janeiro: Zahar, 2010.

HERMET, G. A democratização dos países emergentes e as relações entre o Estado, as OIGs e as ONGs. In: MILANI, C.; ARTURI, C.; SOLINÍS, G. (Orgs.). Democracia e governança mundial: que regulações para o século XXI? Porto Alegre: Editora da Universidade/UFRGS; UNESCO, 2002. p. 33-46.

. La governance serait-elle le nom de l'après-democratie? l'inlassable quête du pluralisme limité. In: HERMET, G.; KAZANCIGIL, A.; PRUD'HOMME, J. (Orgs.). La gouvernance: un concept et ses applications. Paris: Karthala, 2005. p. 17-47. 2005 .

.; KAZANCIGIL, A.; PRUD’HOMME, J. La gouvernance: un concept et ses applications. Paris: Karthala,

INSTITUTO MAIS. México: evento paralelo à COP 16 discutiu cultura de sustentabilidade e ações orientadas pela sociedade civil. 2010. Disponível em: <http://maisinstituto.blogspot.com/2010/12/evento-no-mexico-paralelo-cop16.html>. Acesso em: 25 nov. 2010.

INTERGOVERNMENTAL PANEL ON CLIMATE CHANGE (IPCC). Climate change 2007: synthesis report. Contribution of working groups I, II and III to the Fourth Assessment Report of the Intergovernmental Panel on Climate Change [Core writing team: PACHAURI, R. K; REISINGER, A. (Eds.)]. IPCC, Genève, 2007. 104 p.

INTERNATIONAL INSTITUTE FOR SUSTAINABLE DEVELOPMENT. Sustainable development: from Brundtland to Rio 2012. New York, 2010.

KAFRUNI, S. Eike Batista desiste de construir estaleiro em Santa Catarina. Jornal Diário Catarinense, Florianópolis, 16 nov. 2010. Disponível em: <http://www.clicrbs.com.br/diariocatarinense/jsp/default.jsp?uf=2\&local=18\&section= Economia\&newsID=a3111576.htm $>$. Acesso em: 25 nov. 2010

KARNS, M. P.; MINGST, K. A. International organizations: the politics and processes of global governance. 2 . ed. Boulder: Lynne Rienner Oublishers, 2010. 633 p.

KAUL, I.; GRUNBERG, I.; STERN, M. (Eds.). Global public goods international cooperation in the 21st century. Nova York: Oxford University Press, 1999.

KAZANCIGIL, A. La gouvernance et la souveraineté de 1'Etat. In: HERMET, G.; KAZANCIGIL, A.; PRUD'HOMME, J. (Orgs.). La gouvernance: un concept et ses applications. Paris: Karthala, 2005. p. 49-64.

LAGO, A. A. C. do. Estocolmo, Rio, Johannesburgo: o Brasil e as três conferências ambientais das Nações Unidas. Brasília, DF: FUNAG, 2006.

LECA, J. La gouvernance de la France sur la Cinquième Republique. In: D'ARCY, F.; ROUBAN, L. De la V.e Republique de l'Europe. Paris: Presses de Sciences Po, 1996.

LEFTWICH, A. Governance, democracy and development in the Third World. Third World Quarterly, v. 14, n. 3, p.605-624, 1993.

MILANI, C. La globalisation des organisations internationales et le débat sur la gouvernance. In: BEAUD, M.; DOLLFUS et alii (Orgs.) Mondialisation: les mots et les choses. Paris: Karthala, 1999. p. 169-185. 
; SOLINÍS; G. Pensar a democracia na governança mundial: algumas pistas para o futuro. In: MILANI, Carlos; ARTURI, C.; SOLÍNÍS, G. Democracia e governança mundial: que regulações para o século XXI? Porto Alegre: Editora da UFRGS, 2002

MOTTA, R. S. da et al. Mudança do clima no Brasil: aspectos econômicos, sociais e regulatórios. Brasília, DF: Ipea, 2011. 440p.

NOVAES, W. Ozônio. Programa Repórter Eco - TV Cultura. Disponível em: $<\mathrm{http}$ ://www2.tvcultura.com.br/reportereco/artigo.asp?artigoid=226>. Acesso em: 25 nov. 2010.

OLIVEIRA, C. C. A Rio+20 e a participação da sociedade civil. Pontes, v. 8, n. 2, p.1-3, abr. 2012.

ONU NO BRASIL. A ONU e o meio ambiente. Disponível em: <http://www.onu.org.br/a-onu-em-acao/a-onu-e-omeio-ambiente/>. Acesso em: 8 fev. 2012

PRIER, P. L'Égypte menace de faire la guerre pour les eaux du Nil. Le Figaro, Paris, 16 mai. 2010. Disponível em: $<$ http://www.lefigaro.fr/international/2010/05/16/01003-20100516ARTFIG00169-l-egypte-menace-de-faire-la-guerrepour-les-eaux-du-nil.php>. Acesso em: $15 \mathrm{dez} .2010$.

RADAR RIO+20. A Rio+20 que não queremos. Disponível em: $<$ http://www.radarrio20.org.br/index.php?r=cobertura/view\&id=83>. Acesso em: 30 jun. 2012.

RIO+20. Portal da Rio+20 - Conferência das Nações Unidas sobre Desenvolvimento Sustentável. Disponível em: $<\mathrm{http}$ ://www.rio20.gov.br/?set_language=pt-br>. Acesso em: 2 jul. 2012.

ROSENAU, J. N.; CZEMPIEL, E. (Eds.). Governance without government: order and change in world politics. Cambridge: Cambridge University Press, 1992.

SANTANA, J. S.; GUEDES, C. A. M.; VILLELA, L. E. Desenvolvimento territorial sustentável e desafios postos por megaempreendimentos: o caso do município de Itaguaí - RJ. Cad. EBAPE.BR, v. 9, n. 3, p. 846-867, set. 2011.

TAGUCHI, C. A guerra da água. Disponível em: <http://www.terrazul.m2014.net/spip.php?article311>. Acesso em: 15 dez. 2010.

TRIBUNAL DEL AGUA. História. 2009. Disponível em: <http://www.tragua.com/index.html>. Acesso em: 9 nov. 2010 .

UN DEPARTMENT OF ECONOMIC AND SOCIAL AFFAIRS. UN Commission on Sustainable Development. About the CSD. 2009. Disponível em: <http://www.un.org/esa/dsd/csd/csd_index.shtml>. Acesso em: 5 nov. 2010.

UNITED NATIONS ENVIRONMENT PROGRAMME (UNEP). About UNEP. Disponível em: <www.unep.org>. Acesso em: 5 nov. 2010.

WEAVER, C. E. Hipocrisy trap: the World Bank and the poverty of reform. Princeton: Princeton University Press, 2008 .

ZECCHINI, L. Palestina: Israel faz guerra pela água nos territórios ocupados. Le Monde - Paris. Tradução de Carlos Gorito. 2009. Disponível em: <http://www.correiointernacional.com/archives/1913>. Acesso em: 10 dez. 2010. 